\title{
Global cancer disparity highlighted
}

In this issue of the Journal of Neuroscience in Rural Practice, Kumar et al. present a retrospective study of patients with glioblastoma, a uniformly fatal brain tumor, from their institution in rural India. ${ }^{[1]}$ They report strikingly worse overall survival than similar studies recently reported in the literature from centers in the United States of America. ${ }^{[2]}$ In the subgroup analyses, however, they showed that the small subset of patients who were offered the current standard of care for this disease (which includes radical surgery, adjuvant radiation therapy with concomitant and then further adjuvant temozolomide) fared just as well their counterparts in the USA. This highlights the fact that the source of the difference in outcome is not related to geography, background health status or differing skills of the physicians, but is simply an issue of access to current medical resources.

At the recent "World Oncology Forum" (http://www.eso. net/varie/wof.html), hosted by the European School of Oncology, 100 leading oncology scientists, practitioners and representatives from the media and industry met and discussed the state of worldwide cancer research and care delivery. The three focus points were further research, better preventive strategies and, finally, establishment of parity in global cancer treatment. A final session, hosted by the editor of The Lancet, Richard Horton, agreed key strategies that will be essential to reverse the current escalation of new cases and deaths. On World Cancer Day, an international appeal was launched for governments to commit to these key strategies, which focus on better prevention, accelerating progress in finding cures and giving all patients access to an essential package of treatments. ${ }^{[3,4]}$ The latter point speaks directly to the outcomes reported in this paper. If all patients treated in this study had had access to affordable temozolomide, the subset analysis suggested that the overall outcomes could have been drastically improved, bringing their overall results into

\begin{tabular}{|l|l|}
\hline \multicolumn{2}{|c|}{ Access this article online } \\
\hline Quick Response Code: & Website: \\
\hline & www.ruralneuropractice.com \\
\cline { 2 - 3 } & \\
\hline & DOI: \\
\hline
\end{tabular}

parity with their US counterparts. In this disease, where nihilism has ruled the day, we are starting to finally make progress. Indeed, overall survival has nearly doubled in the last 20 years. While this progress is not as striking as in some cancers, the loss of life to those without access to medications and appropriate therapy is inexcusable.

This coming year, many of us in the global cancer community have decided to take a stand, and we have issued a proclamation to "Stop Cancer Now." This is in coordination with a United Nations summit on non-communicable diseases (NCDs), which has established a global target to reduce premature mortality by $25 \%$ by $2025 .{ }^{[5]}$ To help reach that, the World Health Organization has agreed to reach an $80 \%$ availability of essential drugs and diagnostics in both the public and the private sectors (right now, the availability is around $36 \%$ in the public sector for NCD drugs. ${ }^{[6]}$ The world has stood up before for selected infectious diseases, and, in the fight for health for all, the world is now starting to stand up for cancer and related NCDs. The real question is how do we put this into motion and, in specific, how do we minimize the treatment gap for cancer?

The case of India provides a cogent example - one that involves communities, academics and politicos. For the first time in the Indian history, the country has pledged to fully subsidize all medicines (including imatinib) on the Indian Essential Medicines List in the public sector. This has been a movement, one in which patients have had a say in. It is perhaps telling that just this past year the country has issued its first compulsory license to expedite generic production of an anti-neoplastic (sorafenib). The country is also scaling up public health workers, human resources for health and community health workers to meet the demands of chronic care in the modern era. The issue of getting access to treatment (not just medicines) is nothing new; we have done this before and can do it easily for cancer, particularly by integrating cancer into long-term health system schemes and focusing on proven solutions like generic production. ${ }^{[7,8]}$

While the challenge of getting typically high-cost, limited resources is great, the consequences of failing to do so are even greater. In the article by Kumar et al., ${ }^{[1]}$ we have been shown exactly this downside: Patients with a known disease, with a well-established standard of care, under 
the care of astute academic physicians who do not have the capability to deliver the care they know is best because of issues pertaining to access. This is an injustice that the world is, we hope, starting to understand and address, and, without the diligence and accurate reporting of these authors, this sort of disparity would often be overlooked.

\section{Sandeep Kishore, Jacob Scott ${ }^{1}$}

Weill Cornell/The Rockefeller University/Sloan-Kettering Institute, New York, ${ }^{1} \mathrm{H}$. Lee Moffitt Cancer Center and Research Institute, Tampa, FL, USA

Address for correspondence: Dr. Jacob Scott,

H. Lee Moffitt Cancer Center, Tampa, FL 33612, Tampa, USA. E-mail: jacob.g.scott@gmail.com

\section{References}

1. Kumar N, Kumar P, Angurana SL, Khosla D, Mukherjee KK, Aggarwal R,
Kumar R, Bera A, Sharma SC. Evaluation of outcome and prognostic factors in patients of glioblastoma multiforme-a single institution experience. J Neurosci Rural Pract 2013;4(Suppl 1):s46-55.

2. Scott JG, Suh JH, Elson P, Barnett GH, Vogelbaum MA, Peereboom DM, et al. Aggressive treatment is appropriate for glioblastoma multiforme patients 70 years old or older: A retrospective review of 206 cases. Neuro Oncol 2011;13:428-36.

3. Stop Cancer Now!, Cancer World magazine. Available from: http://www. cancerworld.org/Articles/Issues_52/Systems_\%E7e\%E7_Services/ Stop_Cancer_Now\%21.html [Last accessed on 2013 Jan 1].

4. Stop Cancer Now. Lancet 2013;381:426-7.

5. Availablefrom:http://www.who.int/bulletin/volumes/89/6/10-084327/ en/index.html [Last accessed on 2013 Jan 1].

6. Promotion of access to essential medicines for non-communicable diseases: Practical implications of the UN political declaration. Lancet 2013;381:680-9.

7. Access to Cancer Medicine in low resource setting, Lancet Oncol 2013;14:1.

8. Available from: http://www.who.int/mediacentre/news/notes/2012/ ncd_20121109/en/index.html [Last accessed on 2013 Jan 1].

How to cite this article: Kishore S, Scott J. Global cancer disparity highlighted. J Neurosci Rural Pract 2013, 4(Suppl 1):s1-2.

Source of Support: Nil. Conflict of Interest: None declared.

\section{“QUICK RESPONSE CODE” LINK FOR FULL TEXT ARTICLES}

The journal issue has a unique new feature for reaching to the journal's website without typing a single letter. Each article on its first page has a "Quick Response Code". Using any mobile or other hand-held device with camera and GPRS/other internet source, one can reach to the full text of that particular article on the journal's website. Start a QR-code reading software (see list of free applications from http://tinyurl.com/yzlh2tc) and point the camera to the QR-code printed in the journal. It will automatically take you to the HTML full text of that article. One can also use a desktop or laptop with web camera for similar functionality. See http://tinyurl.com/2bw7fn3 or http://tinyurl.com/3ysr3me for the free applications. 